\title{
An Uncommon Textbook: Review of Common Sense Mathematics by Ethan Bolker and Maura Mast
}

\author{
Bernard Madison \\ bmadison@uark.edu
}

Follow this and additional works at: https://digitalcommons.usf.edu/numeracy

Part of the Adult and Continuing Education Commons, Communication Commons, Higher Education Commons, Mathematics Commons, and the Science and Mathematics Education Commons

\section{Recommended Citation}

Madison, Bernard. "An Uncommon Textbook: Review of Common Sense Mathematics by Ethan Bolker and Maura Mast." Numeracy 12, Iss. 1 (2019): Article 16. DOI: https://doi.org/10.5038/1936-4660.12.1.16 


\title{
An Uncommon Textbook: Review of Common Sense Mathematics by Ethan Bolker and Maura Mast
}

\author{
Abstract \\ Ethan D. Bolker and Maura B. Mast. 2016. Common Sense Mathematics.(Washington DC.: Mathematics \\ Association of America) ISBN-13: 978-1-93951-210-9. \\ Common Sense Mathematics is an integrative quantitative reasoning (QR) textbook that is built around \\ scores of exercises derived from authentic circumstances from public media and other public sources. \\ The exercises elicit responses from students requiring extensive communication and analyses and \\ distinguish the book from ones typically encountered in a mathematics or science course. Responses to \\ exercises often require one-half page or more of writing and can occupy considerable class time in \\ discussion. The book has material for a one- or two-semester course. Use of the Internet for information \\ is assumed, and the use of spreadsheet technology is incorporated but can be avoided for portions of the \\ latter chapters.

\section{Keywords} \\ quantitative literacy, quantitative reasoning, higher education, problem solving, news items

\section{Creative Commons License}

\section{(c) (i) (9)} \\ This work is licensed under a Creative Commons Attribution-Noncommercial 4.0 License

\section{Cover Page Footnote} \\ Bernard L. Madison is emeritus professor and former Chair of the Department of Mathematical Sciences, \\ University of Arkansas, and former Dean of its Fulbright College of Arts and Sciences. He was founding \\ president of the National Numeracy Network and is a frequent contributor to this journal.
}




\section{Introduction}

About a dozen years ago, I visited University of Massachusetts Boston as an evaluator of a quantitative reasoning (QR) course that Maura Mast was developing and teaching. At that point, it was difficult for me to understand what the course would eventually become. I was developing a similar course at the University of Arkansas and could detect some similarities and some differences between the fledgling Arkansas course and the UMass course. Neither course had at that time any published resource material, much less a "textbook." Over the next decade, that changed, and the result at UMass is Common Sense Mathematics by Ethan Bolker and Maura Mast, published by the Mathematical Association of America. It is delivered in hardback or electronically. The Arkansas course eventually landed on Case Studies for Quantitative Reasoning: A Casebook of Media Articles by Madison et al. (2011) published by Pearson Learning Solutions. ${ }^{1}$ Contrasting and occasionally comparing these two publications will help give the reader a sense of Common Sense.

The Arkansas book, hereafter Casebook, contains case studies of 30 complete media articles, each with warm-up questions and study questions about the article. Hundreds of brief scenarios from various media articles and other public sources create the structure of Common Sense. One of the important similarities is that both books focus almost entirely on authentic contextual situations for questions and problems. The few exceptions are in the form of the warm-up questions for each case in the Casebook and the review questions in Common Sense that occur at the end of nine of the thirteen chapters. Teaching from Common Sense, I often thought that the review exercises should be at the beginning of a chapter's exercises, rather than at the end of the exercise set. If doing so serves a class better, it is a simple adaptation.

\section{Exercises in Common Sense}

Six of the thirteen chapters have 14-19 exercises, four have 24-34, and three have 50, 52, and 66. Chapters 1-7, 9, and 12 have review exercises; four of the latter chapters have no review exercises. Most of the exercises begin with a brief description of a scenario, often relying on an excerpt from a media source. The description is followed by questions that derive from the situation. There are hints to possible answers to some of the exercises in the back of the book, and the exercises have tags that indicate their nature (e.g., "untried," "worthy," "complex," or "routine"). One of the challenges in teaching from Common Sense is choosing exercises to assign or discuss in class. Instructors should never assign

\footnotetext{
${ }^{1}$ For review in Numeracy, see Tunstall (2015).
} 
an exercise unless they have composed a possible solution and prepared for many variations of worthy solutions from students. The Common Sense solutions manual (highly recommended by this reviewer) contains sample solutions to many of the exercises. Some of the exercises cry out for extensive discussion; taking an entire class period on just one exercise is not unusual. Student-produced solutions can require half or three-quarters of a page of writing and explanation. Assigning two to three exercises for homework is quite normal. This rigor, of course, aims at one major goal of a course on quantitative reasoning: to go beyond the mathematical representations and calculations to interpretations, analysis, and communication.

\section{Content and Coverage}

Like Casebook, Common Sense is not organized by mathematical topics. Chapters do not begin with development of mathematical material. Rather, chapters begin with stories that prompt common-sense considerations, and the mathematics required is developed as needed. For students with limited mathematics preparation, some supplementary material may be needed. This reviewer found that to be the case with beginning students at Arkansas. For general education students who have no previous QR courses, there is enough material in Common Sense for a two-semester course. Typical coverage for a onesemester course would be chapters $1-5$ with selections from chapters $6-13$. The approximate topical content foci include numerical awareness and estimation, financial mathematics, and risk. Of course, the ideas in these topics have wide application in everyday activities, and these are exploited in the Common Sense exercises.

\section{Technology}

Teaching from Common Sense normally relies heavily on use of the Internet for information. Google was a constant aid in my classes using Common Sense, and I encouraged the students to use Google with the caveat that they report the use (as well as their sources) when writing a solution. Use of a four-function calculator is expected, and possibly a graphing calculator in latter chapters. Beginning in Chapter 6 Excel is used, but not necessary for all exercises.

\section{Quantitative Reasoning Core Competencies}

As developed by an Association of American Colleges and Universities (AAC\&U) panel of collegiate faculty and refined by Boersma et al. (2011), six core competencies are required for $\mathrm{QR}$ : interpretation, representation, calculation, 
analysis/synthesis, assumption, and communication. One way to assess course materials for a course in $\mathrm{QR}$ is to determine how frequently each of these core competencies is required to complete exercises. These six competencies have received various levels of attention as the $\mathrm{QR}$ movement has developed and matured. The historical variation of these levels is reflected in what Maguire and O'Donoghue (2002) have described as three phases of the historical development of QR (called numeracy) - formative, mathematical, and integrative.

The first phase considered QR (or QL or numeracy) as the mirror image of literacy in the most rigorous sense with interpretation and calculation being dominant. The time span of this phase was approximately 1950-1980. The second phase from about 1980 until 2000 considered QR to be based on the mathematical skills useful or required in everyday activities, with representation and calculation being dominant. It was during this time that the Mathematical Association of America (MAA) issued its only description of QR (Sons 1994), and this description has been the basis of several QR courses developed by mathematics departments over the past 20 years (see Sons 2019, in this issue). The integrative phase of QR began in the U.S. circa 2000 with the publication of Mathematics and Democracy (Steen 2001). During this phase, still developing, QR was considered more integrative of other aspects of learning development, namely interpretation, analysis/synthesis, assumption, and communication. Common Sense is very much a product of the integrative phase of $\mathrm{QR}$, as is Casebook.

As part of his $\mathrm{PhD}$ dissertation research at the University of Arkansas, David Deville compared and contrasted three QR courses: a course at a Midwestern university with text material based on the MAA

Table 1

Frequency of AAC\&U Core Competences in Three QR Courses*

\begin{tabular}{lccc} 
& \multicolumn{2}{c}{ Arkansas courses } & Non-Ark \\
& Casebook & Common Sense & MAA Report \\
\hline interpretation & 65 & 31 & 15 \\
representation & 29 & 23 & 17 \\
calculation & 43 & 48 & 55 \\
analysis/synthesis & 34 & 21 & 18 \\
assumptions & 6 & 3 & 1 \\
communication & 23 & 11 & 6 \\
\hline
\end{tabular}

Notes: Numbers are in percent of the questions; they do not add to $100 \%$ description of QR and two courses at the University of Arkansas (Deville 2018). One of the Arkansas courses used Common Sense as its primary text material and the other used Casebook. The non-Arkansas course used a customized workbook fashioned in full view of the MAA description of QR. The authors of the Casebook had earlier mapped their 234 study questions of the 24 case studies to the AAC\&U core competences with the results shown in the first column of Table 1 (from (Boersma et al. 2011, Table 3). Deville mapped the exercises from Chapters 5, 8, and 12 of Common Sense (51 in total, excluding the review exercises), with the results shown in the second column of Table 1. This clearly places Common Sense with the Casebook in the integrative category when 
compared to a similar mapping of a sample of more than 100 exercises from five modules of the textbook for the non-Arkansas course based on the MAA report (third column of Table 3).

\section{Concluding Thought}

One of the issues facing a mathematics department (or any other disciplinary department) is having instructors prepared to teach from Common Sense. Confirmed through various reports from students (e.g., David Deville's interviews of former Common Sense students), such courses are not your usual mathematics (or science, or sociology, or statistics, etc.) course. Instructors must adapt to teaching and evaluating discussions that are integrative, thus involving all six QR core competencies. In the process, the instructors' supply of applications of basic mathematics to introductory college courses is vastly expanded.

\section{References}

Association of American Colleges and Universities. 2009. Association of American Colleges and Universities Quantitative Literacy VALUE Rubric. Accessed August 22, 2018. https://www.aacu.org/value/rubrics/QuantitativeLiteracy.

Boersma, Stuart, Caren Diefenderfer, Shannon W. Dingman, and Bernard Madison. 2011. "Quantitative Reasoning in the Contemporary World, 3: Assessing Student Learning." Numeracy. 4(2): Article 8. https://doi.org/10.5038/1936-4660.4.2.8.

Bolker, Ethan, and Maura Mast. 2016. Common Sense Mathematics. Washington, DC: MAA Press.

Deville, David. 2018. Identifying Opportunities that Promote a Habit of Mind in the Quantitative Reasoning Classroom. PhD dissertation. University of Arkansas.

Madison, Bernard, Stuart Boersma, Caren Diefenderfer, and Shannon Dingman. 2011. Case Studies for Quantitative Reasoning: A Casebook of Media Articles. Pearson Education.

Maguire, T, and J. O’ Donoghue. 2002. “A Grounded Approach to Practitioner Training in Ireland: Some Findings from a National Survey of Practitioners in Adult Basic Education.” Numeracy for Empowerment and Democracy? Proceedings of the 8th International Conference of Adult Learning Mathematics, edited by Lene O. Johansen and Tine Wedege, 120-132. Roskilde, Denmark: Roskilde University, Centre for Research in Learning Mathematics. Stevenage, UK: Avanti Books. 
Sons, L. R., ed., 1994. Quantitative Reasoning for College Students: A Complement to the Standards. Washington, DC: Mathematical Association of America.

Sons, L. R. 2019. The Sons Report (1989-1994). Numeracy 12(1): this issue.

Steen, Lynn A. ed. 2001. Mathematics and Democracy: The Case for Quantitative Literacy. Princeton, NJ: National Council on Education and the Disciplines.

Tunstall, Samuel Luke. 2015. "Review of Case Studies for Quantitative Reasoning: A Casebook of Media Articles by Bernard L. Madison, Stuart Boersma, Caren L. Diefenderfer, and Shannon W. Dingman." Numeracy 8 (1): Article 12. https://doi.org/10.5038/1936-4660.8.2.12. 